\title{
Ensino superior na ótica dos organismos internacionais
}

\section{Higher education in the perspective of international bodies}

\author{
Olgaíses Cabral Maués*
}

\begin{abstract}
RESUMO
O artigo tem como objetivo a análise das posições de organismos internacionais relativas à reconfiguração do papel da educação superior na contemporaneidade em função das exigências feitas pela sociedade do conhecimento, o que é imperioso para a formação do cidadão global para enfrentar os grandes desafios do mundo e as demandas da humanidade.

Palavras-chave: Organismos Internacionais. Ensino Superior. Mundialização. Sociedade do Conhecimento.
\end{abstract}

\begin{abstract}
The paper aims at the analysis of the positions of international bodies relating to the reconfiguration of the role of higher education in contemporary times, based on the demands made by the knowledge society, what is essential for the formation of global citizen to face the great challenges of the world and the demands of humanity.
\end{abstract}

Keywords: International Bodies. Higher Education. Globalization. Knowledge Society.

O ensino superior tem sido visto, nos últimos 20 anos, como uma ferramenta que pode alavancar o desenvolvimento econômico de um país. A lógica que preside esse pensamento tem levado os governantes a elaborarem políticas educacionais, visando contribuir com as demandas de um mundo globalizado e mundializado. A abordagem dessa questão, valorização do ensino superior

*Universidade Federal do Pará. Belém, Pará, Brasil. E-mail: olgaises@uol.com.br. https:// orcid.org/0000-0002-6012-1432. 
enquanto promotor do crescimento econômico, tem, por vezes, desfigurado/ reconfigurado a face até então conhecida desse nível de ensino, alterando suas finalidades, sua estrutura e forma de organização administrativa e acadêmica.

As alterações contemporâneas, que vêm ocorrendo nas sociedades, têm afastado as universidades dos modelos humboldtiano ${ }^{1}$ e napoleônico ${ }^{2}$, que foram se diluindo e outros elementos foram sendo incorporados à concepção do que se tinha das funções e dos objetivos do ensino superior. A Organização para a Cooperação e o Desenvolvimento Econômico (OCDE) (2011) analisa que, em função da "nova gestão pública" (NGP) ${ }^{3}$, a universidade se distancia pouco a pouco do modelo humbolditiano e se aproxima cada vez mais do mercado.

O contexto sócio-político tem uma grande influência no tocante às mudanças que têm ocorrido no ensino superior, tanto na formatação da estrutura organizativa, quanto na lógica que deve presidir suas finalidades, não esquecendo a correlação de forças internas e externas que contribuem para a conformação dessa instituição de ensino.

A partir dessas considerações iniciais, o presente artigo tem como objetivo principal analisar as 'recomendações' que alguns organismos internacionais, com destaque para o Banco Mundial (BM) e a OCDE, vêm apresentando aos países e governos, no sentido de adequar o ensino superior a essas transformações, à mundialização e à chamada sociedade do conhecimento.

Em um primeiro momento, neste texto, será analisado os fenômenos da mundialização e da sociedade do conhecimento, procurando-se fazer a relação com as orientações dos organismos internacionais para o ensino superior. No contexto dos novos paradigmas, trazidos pelas mudanças econômicas e sociais, será analisado o ensino superior no Brasil, buscando-se considerar as possíveis

1 "O modelo humboldtiano assume a universidade como uma instituição que goza de autonomia relativa na produção do conhecimento, [...]. Põe a pesquisa científica no centro das relações universitárias, enfatizando a indissociabilidade entre ensino, pesquisa e formação geral, humanista e científica, com foco na totalidade universalidade do saber" (SILVEIRA; BIANCHETTI, 2016, p. 84).

$2[\ldots]$ " O modelo napoleônico de universidade, caracterizado por escolas isoladas de cunho profissionalizante, com dissociação entre ensino e pesquisa e grande centralização estatal" (PAULA, 2002, p. 156).

3 A NGP nasce com as ideias neoliberais, na Inglaterra. "Alguns de seus princípios podem ser observados nas reformas que ocorreram nas últimas décadas em diferentes contextos nacionais, sendo eles: a dissociação das funções de execução e controle; a fragmentação das burocracias e sua abertura às demandas e exigências dos usuários; a concorrência de atores públicos com o setor privado e a terceirização dos serviços; o reforço das responsabilidades e da autonomia dos níveis de execução da ação pública; a gestão por resultados e a contratação (os chamados contratos de gestão) fundadas na realização dos objetivos e da avaliação de desempenho; a normalização, via padronização, das práticas profissionais baseadas em evidências e em experimentos exemplares" (OLIVEIRA, 2015, p. 631). 
influências dos OI presentes nas alterações por ele sofridas, levando em conta um certo período de tempo, na ocorrência, os anos de 1990 e as duas primeiras décadas do século XXI. Finalmente, procura-se identificar e fazer considerações acerca das novas tendências do ensino superior, originárias da ressignificação do papel e das funções que esse nível passa a assumir, a partir das orientações e diretrizes emanadas pelos organismos internacionais, no sentido de uma adequação à nova etapa do capitalismo.

\section{A mundialização e a sociedade do conhecimento}

A manifestação da mundialização trouxe novas exigências e forjou a sociedade do conhecimento. Neste texto, abraçamos o conceito de mundialização a partir de uma visão crítica, entendendo que se trata de um processo que contribui para a valorização do capital.

Chesnais (1996, p. 32) é bem claro quando diz que a "mundialização deve ser pensada como uma fase específica do processo de internacionalização do capital e de sua valorização", alertando para o fato de que os seus fundamentos são tanto políticos como econômicos, não sendo esse fenômeno de mundialização, natural, mas resultante de intervenções que se originam tanto do mundo das finanças quanto do próprio Estado. Harnecker (2002) explicita que a mundialização é uma nova fase da internacionalização do capital, tendo criado um mercado global de capitais, facilitando a acumulação em escala planetária. Mészáros (2002) defende que a mundialização é uma outra etapa do capital. Isso significa, para o autor, que a fase anterior do capitalismo perdeu sua razão de ser, que é a capacidade expansiva, resultando em uma crise no sistema do capital.

Na lógica desses autores supra citados, a mundialização está voltada para o fortalecimento da sociedade capitalista, ampliando seus domínios, transformando o mundo em mercadoria e interferindo diretamente nos aspectos sociais, políticos, econômicos e financeiros da sociedade. Essa etapa do capitalismo teria como distintivo a mobilidade do capital e a predominância da esfera financeira.

A OCDE (2011) defende que a mundialização estimula as mutações econômicas e culturais, formando mercados mundiais que funcionam em tempo real no seio de sistemas financeiros comuns, propiciando um nível elevado de investimentos diretos no exterior, facilitando a mobilidade transfronteira da produção.

Para o Banco Mundial (2002, p. 10), a "mundialização, isto é, a integração progressiva dos sistemas econômicos e das sociedades em escala global, é um processo complexo que envolve muitos aspectos de nossa existência”. O 
BM defende a mundialização enquanto um fator importante para a redução da pobreza, tendo em vista que os sistemas econômicos estão integrados e o crescimento tende a ser mais rápido e a se generalizar, alcançando todos os países. A lógica do BM é de que, na medida em que os países pobres têm acesso ao mercado internacional de produtos manufaturados e de serviços, as populações desfavorecidas têm a possibilidade de conseguir melhores trabalhos.

Em outras palavras, e fazendo a defesa dessa ideia, a Organização de Cooperação para o Desenvolvimento Econômico e o Banco Mundial avalizam a posição de Chesnais (1996), Harnecker (2002) e Mészáros (2002), qual seja, a mundialização contribui para a internacionalização do capital, aumentando os seus domínios, derrubando barreiras e fronteiras e possibilitando a abertura e expansão de mercados.

É nessa sociedade, na qual domina a mundialização financeira, que o conhecimento se transformou em força produtiva e a educação virou mercadoria. Nesse contexto, é inventada a sociedade do conhecimento. Para Duarte (2008, p. 13), "a assim chamada sociedade do conhecimento é uma ideologia produzida pelo capitalismo, é um fenômeno no campo da reprodução ideológica do capitalismo". Mari (2006, p. 21) faz uma análise crítica do termo e informa que “as discussões em torno do tema 'sociedade do conhecimento' não são pacíficas dada a multiplicidade de significados [...] [tendo] sentido polissêmico, ambíguo, abrangendo conhecimento, informação, tecnologia e comunicação". Este autor faz críticas à chamada sociedade do conhecimento que, na concepção de seus idealizadores ${ }^{4}$, representaria uma sociedade mais harmônica, indicando caminhos para o desenvolvimento das economias dos países periféricos, legitimando a globalização e justificando "as ações do governo e agências internacionais na condução de políticas de interesse hegemônicos" (MARI, 2006, p. 23). Theis (2013, p. 133) critica a chamada sociedade do conhecimento, que, para os seus defensores "seria amparada por uma nova economia, fundada no uso cada vez mais intensivo de informação e conhecimento". Nessa suposta sociedade do conhecimento, ou em uma sociedade pós-capitalista, a exploração deixaria de existir e os trabalhadores seriam bem remunerados, enquanto "operários do saber".

Bernheim e Chaui (2008) fazem uma análise sobre a dita sociedade do conhecimento. Os chamam a atenção para o surgimento de um "novo paradigma econômico e produtivo no qual o fato mais importante deixa de ser a disponibilidade de capital, trabalho, matérias-primas ou energia, passando a ser

4 No livro Uma era de descontinuidade, de 1970, Peter Drucker cunha a expressão sociedade do conhecimento. 
uso intensivo de conhecimento e informação" (BERNHEIM e CHAUI, 2008, p. 7). Os autores citados (2008, p. 7) dão destaque ao fato de que, na sociedade capitalista, "a vantagem comparativa é determinada cada vez mais pelo uso competitivo do conhecimento e das inovações tecnológicas", tornando-se "um pilar da riqueza e do poder das nações", ao mesmo tempo em que "encoraja a tendência a trata-lo [o conhecimento] como mercadoria sujeita às leis do mercado e aberta à apropriação privada", integrando-se ao "capital que começa a depender desses fatores [conhecimento e tecnologia] para a sua acumulação e reprodução".

\section{O ensino superior a a sociedade do conhecimento}

Pelo significado que a educação superior sempre teve, acrescido do valor que a mundialização the outorgou na chamada sociedade do conhecimento, os organismos internacionais passaram a lhe dedicar maior interesse, o que é traduzido, dentre outras formas, por meio de documentos orientadores que trazem diretrizes sobre o assunto e que, por vezes, servem de verdadeiros guias na elaboração de reformas e no estabelecimento de políticas educacionais.

Os organismos internacionais passam a difundir esse tipo de sociedade e defendem que a educação, sobretudo o ensino superior, deve ser a alavanca para a organização e existência dessa nova forma de organização social. O BM (2003) anuncia que o saber se transformou no fator mais importante de desenvolvimento econômico. Esse organismo argumenta que o crescimento econômico é um processo de acumulação tanto de conhecimento como de capitais e exemplifica que os países da OCDE já investem em pesquisa e desenvolvimento, o que o BM (2003, p. 36) chama de "valores imateriais que constituem a base do conhecimento", mais ou o mesmo que gastam em equipamentos.

O Banco Mundial (2003) apresenta indicações muito claras em relação ao papel que a educação terciária ${ }^{5}$ deve desempenhar para a construção da sociedade do conhecimento. Para tanto, elabora um documento, no qual explicita o papel desse nível de ensino para o crescimento econômico de um país. Dentre várias

5 As universidades são parte do sistema de educação terciária, mas há um conjunto diverso e crescente de instituições terciárias públicas e privadas em cada país: institutos de capacitação técnica, faculdades, escolas de enfermagem, laboratório de investigação, centros de excelência, centros de educação a distância e outros, conformam uma rede de instituições sobre os quais se apoia a produção de alta capacidade para o desenvolvimento (BM, 2003, p. 08). 
indicações feitas, destaca-se aquela na qual é propugnada que a educação terciária é fundamental para criar a capacidade intelectual, produzindo e atualizando o conhecimento, como também contribui na construção da capacidade de um país participar de uma economia baseada no conhecimento, impulsionando assim o crescimento econômico e reduzindo a pobreza.

A OCDE (2008) explicita a importância do ensino superior para a construção de uma economia mundial baseada no conhecimento. A Organização defende que essa educação é um poderoso motor para promover a competitividade econômica e, como o Banco Mundial, também esclarece as mudanças dadas ao sentido desse ensino, que passa a ser mais abrangente, mais voltado para os interesses do mercado. Em função disso, mesmo não chamando esse nível de terciário dá o mesmo sentido quando diz que engloba instituições politécnicas, institutos universitários, institutos tecnológicos e é bem clara ao dizer que essa diversificação de instituições surgiu para, dentre outros motivos, estabelecer uma maior ligação com o mercado de trabalho.

Silva Júnior (2017) também alerta para o fato de que o conhecimento se tornou matéria-prima direcionada para a economia e para atender o mercado. Para esse autor, "trata-se do conhecimento pronto para ser transformado em produtos de alta tecnologia, novos processos de produção e serviços e está relacionado a possibilidade de lucros imediatos no âmbito econômico" (SILVA JÚNIOR, 2017, p. 129).

O contexto da mundialização, da qual emerge a sociedade do conhecimento, propiciou o surgimento do capitalismo acadêmico. Essa expressão foi cunhada por pesquisadores norte-americanos, Sheila Slaugther e Larry Leslie, e publicizada em um livro de 1997, denominado Academic capitalism: Politics, policies, and the entrepreneurial university. O sentido que esses autores atribuem a essa 'nova vulgata' é de que houve uma diminuição dos recursos públicos para o ensino superior e esse fato tem obrigado essas instituições a se converterem em unidades que procuram vender seus produtos, no caso o ensino, pesquisa e extensão, com o objetivo de conseguir financiamento para desenvolver seus projetos e buscar lucros na venda de seus produtos.

Silva Júnior (2017) traz uma análise sobre o capitalismo acadêmico e informa que outras denominações são dadas a esse fenômeno, explicitando que, no caso brasileiro, esse regime de capitalismo acadêmico teve início nos governos de Fernando Henrique Cardoso (1995-2002). Este autor apresenta a Teoria do Capitalismo Acadêmico, desenvolvida por Slautgther e Rhoades em 2011, significando a formação de redes entre o setor público e o privado, que articulam "instituições, professores, administradores, profissional acadêmico e estudantes com a Nova Economia, novos investimentos, marketing e comportamento de consumo por parte da comunidade universitária[...]" e os autores 
citados por Silva Júnior completam o sentido que dão a essa Teoria, dizendo que "esses mecanismos e comportamentos constituem um Regime de Conhecimento e aprendizagem capitalista" (SLAUTGTHER; RHOADES, 2010, p. 234 apud SILVA JÚNIOR, 2017, p. 126-127).

Dessa forma, há um interesse e uma convergência em relação à função que o ensino superior deve desempenhar na e para a sociedade do conhecimento. Lembrando Bernheim e Chaui (2008) quando alertam para o papel que essa dita sociedade representa para a autonomia das universidades, instituindo a heteronomia universitária, na qual o mercado e o capital financeiro passam a reger a vida acadêmica na definição da natureza dos cursos, do tipo de pesquisa a ser desenvolvida e da liberdade que pode ser usufruída pela comunidade acadêmica.

\section{A educação superior brasileira}

As transformações que o ensino superior vem sendo submetido não deixaram imune as reformas e as políticas educacionais estabelecidas pelo Brasil, o que tem levado a um distanciamento do perfil da universidade humbolditiana, ou mesmo do modelo napoleônico. Na atualidade, pela legislação brasileira (Lei 9.235/2017), o ensino superior se constitui por Universidades ${ }^{6}$ que desenvolvem ensino, pesquisa e extensão; pelos Centro Universitários ${ }^{7}$, que desenvolvem ensino e extensão e pelas Faculdades ${ }^{8}$ que oferecem apenas o ensino. Pode-se observar que essa diversificação das instituições, que mudou o escopo do ensino, também facilitou a expansão da educação superior pela via privada. O Censo da Educação Superior (MEC, 2016) apresenta dados que comprovam essa assertiva. Das 2.407 instituições existentes, apenas 197 são Universidades, sendo 108 públicas $(54,8 \%)$ e 89 privadas. Em contrapartida, existem $138 \mathrm{Fa}$ culdades públicas e $1.866(88,4 \%)$ Faculdades particulares. Ou seja, a grande concentração de instituições do setor privado está nas entidades que ofertam apenas o ensino. O número de matrículas da educação superior é na ordem de 8.052.254 alunos, sendo que desses, $75,3 \%$ (6.058.623), estão no setor privado e $24.7 \%$ (1.990.078) no setor público.

6 Ter, no mínimo, 1/3 de docente contratados em tempo integral e com curso de mestrado ou doutorado, possuir programa de extensão e de iniciação científica, oferecer cursos de graduação e de pós-graduação stricto sensu.

7 Exigências: 1/5 do corpo docente ter contrato em regime de tempo integral, 1/3 de docente possuir titulação de mestre ou doutor, ter programas de extensão e de iniciação científica.

8 O corpo docente tem de ter, no mínimo, pós-graduação lato sensu. 
O que esses dados podem demonstrar é que, no Brasil, a predominância de estudantes matriculados está na educação terciária, na lógica assumida pela $\operatorname{OCDE}(2008$, p. 04), que explicita que há quarenta anos atrás a expressão ensino superior designava o tipo de ensino ministrado pelas universidades, significando um ensino conceitual, que exigia desenvolvimento intelectual em letras, ciências e ciências humanas. Na atualidade, para esse organismo, o ensino superior representa a diferenciação e engloba vários tipos de estabelecimentos que podem fazer a ligação mais direta com o mundo exterior, abrindo-se mais diretamente às necessidades do mercado. Essa diferenciação já tinha sido recomenda pelo BM em 1994, quando da divulgação do documento L'enseignement superieur: les leçons de l'experience, que indica quatro medidas a serem tomadas pelos governos para tornar o ensino mais eficiente. O Banco defende uma maior diferenciação das instituições e de seus objetivos e o desenvolvimento de instituições não universitárias ${ }^{9}$. Essas medidas aprofundam a diferença entre ensino e pesquisa, criando um ensino pragmático, voltado para formar profissionais alinhados com a visão do mercado.

A educação superior brasileira vem sofrendo as influências da mundialização do capital, tendo, ela própria, se tornado uma mercadoria. Bianchetti e Sguissardi (2017) tratam da questão, evidenciando que esse nível de ensino está sendo "sacrificado no altar do mercado" e que "o futuro da universidade se situaria em algum lugar do passado" (subtítulo do livro). Os autores analisam a mercantilização do ensino superior e utilizam o neologismo commoditycidade para explicitar melhor o que vem acontecendo com o ensino superior em geral, trazendo dados que evidenciam o fenômeno no Brasil. Para Bianchetti e Sguissardi, a commoditycidade significa que as instituições de ensino superior adquiriram as características típicas de empresas mercantis, isto é, que visam lucro.

Bianchetti e Sguissardi (2017, p. 76) analisam a expansão do ensino superior brasileiro, indicando que ela ocorreu não apenas pela via privada, como já demonstrado em outra parte deste texto, mas também se deu pela via privada mercantil, ou ainda, pelo "público-quase-privado". Essas afirmações são respaldadas pelos dados trazidos pelos autores no que se refere, sobretudo, mas não só, às fusões de instituições, à formação de monopólios, as empresas privadas que passam a negociar a mercadoria educação na Bolsa de Valores.

Santos, Guimarães e Chaves (2018) trazem dados importantes sobre a abertura de capital na BM\&FBovespa de empresas educacionais: em 2007,

9As outras 3 medidas são: diversificação do financiamento das instituições públicas e adoção de incentivos para um melhor desempenho e maior mobilização de recursos para as instituições privadas; redefinição da função do governo, estabelecimento de um marco coerente de política, maior autonomia e responsabilidade das instituições públicas; enfoque na qualidade, adaptabilidade e equidade. 
Anhanguera Educacional, Estácio Participações, Sistema Educacional Brasileiro, Kronton Educacional; em 2011, Somos Educação/Abril Educação; em 2013, GAEC Educação/Ânima Educação. Em 2014 houve a fusão do Grupo Anhanguera com o Grupo Kroton, tornando-se o maior grupo de ensino superior do mundo. Esses conglomerados representam hoje o ensino superior privado mercantil, que detêm cerca de $75 \%$ das matrículas no ensino superior e começam a se espraiar também pela educação básica.

As mudanças que o ensino superior brasileiro vem sofrendo têm forte influência dessa concepção do "novo" papel que deve desempenhar, apoiado nas diretrizes emanadas dos organismos internacionais que defendem a importância desse nível de ensino para o desenvolvimento da sociedade do conhecimento, no processo de mundialização do capital.

Chaui (2003) faze uma análise da universidade brasileira e demonstra que houve uma alteração no seu ethos, deixando de ser uma instituição social, para se tornar uma organização social. Essa 'passagem', que Chaui (2003, p.6) assinala, significa que houve uma perda do sentido de "prática social fundada no reconhecimento público de diferenciação, que lhe confere autonomia perante outras instituições" para se tornar uma organização que tem "operações definidas como estratégias balizadas pelas ideias de eficácia e de sucesso no emprego de determinados meios para alcançar o objetivo particular que a define", sendo "regida pelas ideias de gestão, planejamento, previsão, controle e êxito". Dessa forma, segundo o autor citado, a universidade passa a ser operacional, instrumental, funcional, cujas ações estão voltadas para os interesses do capital e não para as demandas sociais.

Na contemporaneidade, a educação superior tem vários modelos e diferentes instituições que são abrigadas dependendo dos escopos apresentados, destacando, sempre, a relação existente entre os formatos administrativos e as finalidades fixadas para esse nível de ensino que, por sua vez, responde à hegemonia da classe no poder, malgrado a luta que se estabelece.

\section{As novas tendências da educação superior e a mundialização}

Para a OCDE (2011), o ensino superior é fundamental para a economia do conhecimento, que é decorrente da mundialização, tendo em vista o papel de servir como elemento catalisador de relações internacionais, intensificando o fluxo mundial de pessoas, informações, conhecimento, tecnologias, produtos e capitais financeiros. Ao mesmo tempo, o ensino superior é visto por esse organismo inter- 
nacional, como aquele que contribui com todas as mudanças que acompanham a mundialização. Nesse sentido, "a pesquisa tem um papel chave para a formação desse novo ambiente mundial, tendo em vista que ela condiciona o conhecimento, a transferência de tecnologias, e a colaboração transfronteira" (OCDE, 2011, p. 23).

Em um documento de 2006, a OCDE traça alguns cenários para o ensino superior. $\mathrm{O}$ documento foi apresentado e debatido no Fórum da reunião de ministros da Educação dos países membros dessa organização. Os cenários apresentados podem ajudar a compreensão das recomendações que vêm sendo apresentadas aos gestores das instituições de ensino superior, avalizadas pelos ministros da educação e governos dos estados-nação.

Em um dos cenários denominado de "rede aberta" a ênfase recai sobre quatro pontos: a internacionalização, o ensino a distância, o uso do inglês e a pesquisa em rede. Em relação à internacionalização, a perspectiva é que se estabeleça uma rede que envolve os estabelecimentos de ensino, os professores, os estudantes e outros atores, como as empresas. Nesse caso, os estudantes escolhem seus cursos em uma rede mundial de ensino pós-secundário e compõem seus programas de estudos, respeitando as convenções internacionais.

A criação dessas redes é facilitada pela utilização das novas tecnologias, permitindo que os estudos sejam feitos a distância, alterando o papel do professor que fica responsável apenas por realizar pequenos seminários. Os cursos serão dados em inglês, mesmo para os países não anglófonos. As pesquisas serão realizadas em rede e os países menos desenvolvidos usufruirão das investigações feitas em outras partes mais avançadas. Um dos cenários do futuro do ensino superior parece já ser uma realidade, ou está prestes a se concretizar. O próprio nome atribuído a essa perspectiva de futuro das universidade já revela bastante o seu conteúdo. Trata-se de "Ensino Superior Corporation". Algumas características desse tipo de ensino superior são: os estabelecimentos de ensino estarão em concorrência internacional para o fornecimento de serviços educacionais e de pesquisa, em uma base comercial; o ensino e a pesquisa estarão cada vez mais 'desconectados', seguindo o que está posto pelo Acordo Geral de Comércio e de Serviços (AGCS). Isso significa que existirão instituições voltadas apenas para o ensino, e outras voltadas para a pesquisa. Uma outra característica desse tipo de instituição de ensino superior é a oferta de ensino profissional que representará uma parte importante do mercado mundial de educação. Haverá uma disputa muito grande pelos estudantes, serão abertas novas instituições no estrangeiro, algumas em regime de franquia, surgindo uma divisão internacional do trabalho, isto é, alguns países se especializarão em ofertas de cursos em nível de graduação e outros em nível de pós-graduação, o que inclui pesquisa. As línguas locais serão utilizadas nas instituições de ensino e o inglês será utilizado nos estabelecimentos que fazem pesquisa e ofertam a pós-graduação. Nesse cenário, é criado um mercado internacional de ensino superior e de serviços de pesquisa. $\mathrm{O}$ 
ensino superior, por orientações externas, aceitas e mediadas pelos governos locais, passa a funcionar para a construção da sociedade do conhecimento, na concepção analisada anteriormente.

Além desses cenários traçados pela OCDE, outros papéis são desenhados para esse nível de ensino. Trata-se da constituição de uma Universidade de Classe Mundial (UCM). Para Thiengo (2018, p. 1), o modelo de World Class University (WCU) vem sendo utilizado como uma forma de induzir as "condições para expansão do capital, [...] a partir da promoção de uma nova cultura institucional pautada pelos fundamentos empresariais, pela seleção de áreas estratégicas para inovação e, especialmente, pela promoção da internacionalização". Esse tipo de universidade tem a excelência como palavra-chave que serve de parâmetro para todas as suas atividades.

Altbach (2004 apud NEVES, 2016, p. 3) enumera sete características de uma universidade de classe mundial, a saber: excelência na pesquisa; liberdade de ensino, pesquisa e extensão; autonomia acadêmica; infraestrutura adequada; financiamento; cosmopolitismo; diversidade. Thiengo, Bianchetti e Mari (2018, p. 717) dizem que, para ser uma Universidade de Classe Mundial, é preciso ter "alto nível de internacionalização (para atração de talentos); investimento alto e diversificado; gestão flexível e transferência de tecnologia/interação com o setor produtivo (inovação), entre outras características". Há uma espécie de complementação das exigências necessárias para que as instituições de educação superior cheguem ao patamar que venha atender ao mundo globalizado. Chama-se a atenção para o aspecto do financiamento, que aparece nas duas caracterizações de UCM e que pode representar um reforço para a privatização.

Para Thiengo, Bianchetti e Mari (2018), o fato de uma instituição de educação superior ter como missão alcançar a excelência pode significar tanto ter qualidade, quanto ser classificada nos rankings internacionais como uma das melhores no mundo. Em geral, o sentido de excelência, na sociedade capitalista, está vinculado à eficiência, a resultados enquanto fatores fundamentais para a ampliação do capital. É preciso que se tenha clareza quais os critérios adotados por essas avaliações internacionais que atribuem notas às entidades. Os organismos internacionais e os países centrais têm tido um papel fundamental nessa caracterização avaliativa que tem como parâmetro o papel que atribuem a essa instituição de ensino superior, em uma sociedade do conhecimento, que contribui para a mundialização da economia.

Silva Júnior (2017, p. 124) informa que a concepção dos Estados Unidos sobre universidade é a chamada Universidade de Classe Mundial que produz um "novo tipo de conhecimento", orientado pela economia mundializada, ou nova economia, no sentido de que tem como característica a predominância financeira (SILVA JÚNIOR, 2017, p. 35). Este autor chama a atenção para o que vem ocorrendo nas universidades, isto é, o estabelecimento de "relações entre a educação superior e a 
predominância financeira", como "característica da economia globalizada" (SILVA JÚNIOR, 2017, p. 118). Pode-se fazer um paralelo entre o que Silva Júnior chama de nova economia e a sociedade da economia ou sociedade do conhecimento abordada neste texto. Isto porque essas expressões, cunhadas e utilizadas a partir da segunda metade do século passado e com maior intensidade no século XXI, remetem para as mudanças que estão sendo exigidas e já ocorrendo nas instituições de ensino superior, quais sejam, a produção de conhecimento "matéria-prima, passível de ser transformado em produtos, processos e serviços" (SILVA JÚNIOR, 2017, p. 127).

Para essa "nova" universidade atingir o objetivo da economia do conhecimento, ou da "nova economia", tem necessidade de modificar seus objetivos, missões, formas de gerenciamento e avaliação, buscando uma modelagem mais próxima ao perfil do mercado, adequando-se ao que se vem denominando de Universidade de Classe Mundial, em uma lógica que privatiza o conhecimento e busca uma relação que mercantiliza o saber.

Para o Banco Mundial (2009), se faz fundamental e premente que os países criem ou transformem suas instituições de ensino superior em Universidades de Classe Mundial. Segundo este organismo internacional, essas instituições se caracterizam pelos resultados excepcionais que apresentam e que são traduzidos pelos egressos altamente qualificados, o que vai representar uma grande aceitação e procura pelo mercado de trabalho; pelas pesquisas que desenvolvem que são consideradas de ponta, em geral publicadas em revistas internacionais; e pelas contribuições às inovações tecnológicas. Para o BM (2009, p. 37), para que essas características possam existir são necessários vários aspectos considerados fundamentais, tais como: professores altamente qualificados; pesquisas de ponta; ensino de qualidade; importantes fontes de financiamento público e privado; estudantes muito bem dotados de inteligência; existência de estudantes internacionais de alto nível; liberdade acadêmica que implica estruturas autônomas e de governança bem definidas e de infraestruturas bem equipadas para o ensino e a pesquisa. Chama a atenção, no documento do BM (2009), a ênfase dada à importância do financiamento das universidade de classe mundial, que, segundo esse estudo, vem, em geral, de doações de empresários que, em uma espécie de mecenato, contribuem para o desenvolvimento do conhecimento. Além dessa fonte, o documento também indica, como fundamental para o financiamento, os contratos de pesquisa que devem ser firmados com as empresas públicas e privadas, além dos fundos públicos e do pagamento de anuidade por parte dos estudantes.

Há, pois, uma tendência induzida, principalmente pelos organismos internacionais e pelo mercado, de que as instituições de educação superior devem se diferenciar, abrindo um leque grande para aquelas que não estão na rubrica de universidades, tais como os institutos e as faculdades; devem também diversificar suas fontes de financiamento, além de haver necessidade de uma mudança efetiva 
no papel do governo/Estado. Tudo isso não é novo, lembrando, e já mencionado neste texto, em 1994, o BM já deixava claro essas "orientações".

$\mathrm{Na}$ contemporaneidade, fala-se da mundialização, da sociedade do conhecimento, da Universidade de Classe Mundial e o Brasil procura se alinhar a essas "novas" diretrizes, sempre emanadas das mesmas fontes, os organismos internacionais. Na realidade, esse perfil de educação superior vem exigindo que a educação superior se internacionalize, para fazer face às demandas da mundialização financeira, que coloca, nesse nível de ensino, a responsabilidade pelo desenvolvimento econômico, na lógica da valorização do capital.

Um exemplo disso, no caso brasileiro, pode ser a Universidade de São Paulo (USP). Em documento confidencial de 2016, intitulado 'Criando as Bases para a USP do Futuro', são colocadas as exigências para essa internacionalização, ou para a consolidação da Universidade de Classe Mundial. O exame do Relatório indica pontos importantes, os quais passaremos a analisar. Inicialmente são apresentadas as Aspirações dessa instituição, as quais enumeramos a seguir: ser reconhecida como uma das melhores Universidades do mundo; atrair e reter os melhores professores da América Latina e do mundo; ser uma referência em pesquisa em um modelo que envolve a parceria público-privado; ser um ponto de conexão do conhecimento do Brasil com o mundo; atrair e reter os melhores talentos do Brasil (USP, 2016).

O relatório da USP (2016) evidencia uma preocupação máxima com a "excelência", o que pode se considerar natural em uma instituição que está votada para a formação humana, por meio do ensino, da pesquisa e da extensão. Mas é preciso que se examine melhor o que é considerado como sendo uma instituição de ensino que tenha excelência.

Para o Banco Mundial, uma instituição de excelência precisa ser uma universidade de pesquisa, com abundância de talentos, entre docentes e discentes, recursos suficientes para desenvolver as atividades e uma governança favorável (BM, 2009, p. 42). Há uma clara posição do BM ao esclarecer que apenas um pequeno número de instituições pode ser de excelência, ou de classe mundial. Há uma nítida divisão entre as instituições de elite, feitas para os filhos da burguesia e as outras instituições, na concepção defendida pelo BM e pela OCDE de instituições terciárias ou de ensino. Para conseguir esse intento, qual seja, construir instituições de excelência, o BM indica algumas estratégias, tais como as de melhorar as instituições existentes, ou fazer a fusão de algumas das melhores instituições do país, ou ainda criar novas instituições.

O relatório da USP (2016) apresenta a situação na qual essa instituição se encontra, em alguns aspectos considerados cruciais na lógica da excelência, como por exemplo o número e publicações e o número de citações, fazendo uma comparação com as instituições mais prestigiosas do mundo, mostrando que essa instituição apresenta um baixo impacto acadêmico. A Figura 1 traz os dados. 


\section{FIGURA 1 - QUADRO DE EXCELÊNCIA ACADÊMICA}

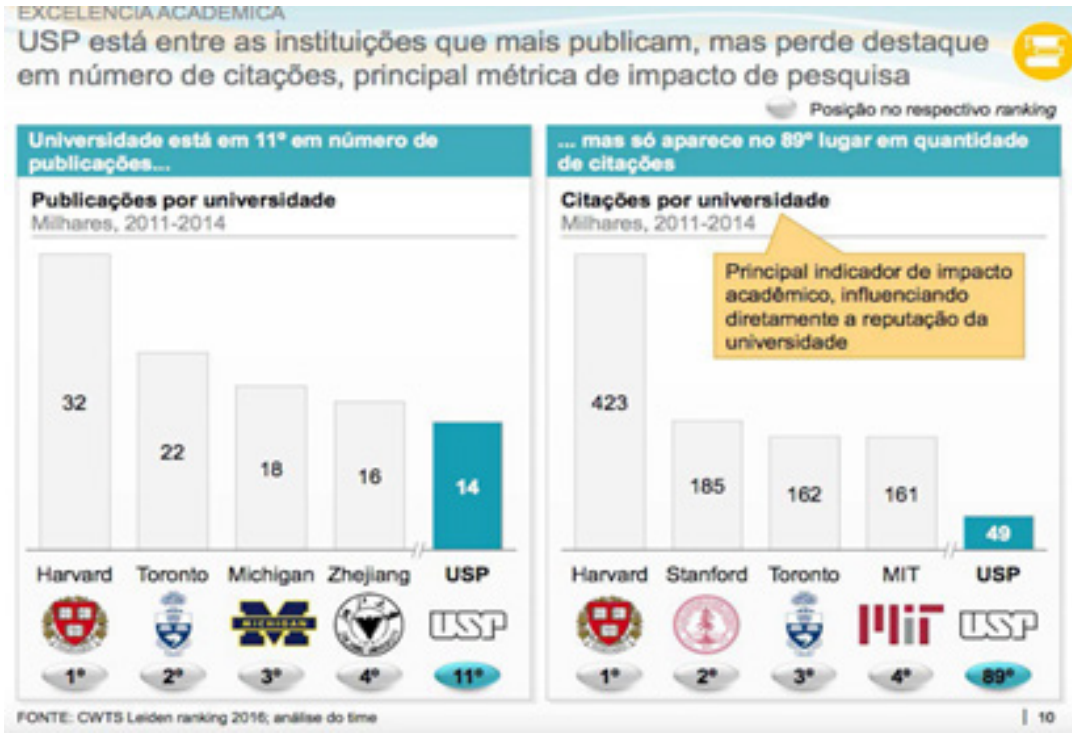

FONTE: USP, 2016.

Outros dados importantes e interessantes são apresentados no relatório em questão que permitem ter uma dimensão dos caminhos que estão sendo propostos para que a Universidade de São Paulo se torne uma Universidade de Classe Mundial. Outros fatores são destacados, com ênfase para as parcerias público-privadas e para a privatização aberta. O relatório apresenta as fontes de financiamento da USP e compara com outras universidades públicas da Europa e dos Estados Unidos, destacando a diversificação das fontes de recursos e evidenciando a importância disso ${ }^{10}$. Os dados da USP são considerados negativos para uma instituição de excelência. O relatório apresenta informações de outros países, com destaque para os Estados Unidos ${ }^{11}$, salientando o fato de que, nos

10 Os dados foram agrupados em 3 itens: Outras fontes de receita (rendimentos de investimentos, receitas de atividades comerciais e doações de particulares); Receita com mensalidades de alunos; Repasses do governo. Os dados apresentados indicam que, no caso da USP, $93 \%$ dos recursos são oriundos do governo e $7 \%$ de outras fontes.

11 Nos EUA, $37 \%$ de recursos do governo, $23 \%$ referentes às mensalidades estudantis e $40 \%$ de outras fontes. 
EUA, apenas $37 \%$ do financiamento das universidades são oriundos do governo, em contraste com o Brasil, especificamente no caso da USP, no qual 97\% dos recursos advém do governo ${ }^{12}$.

Pode-se inferir, a partir desses dados, que o modelo norteamericano de Universidade de Classe Mundial é privatizante e que há uma forte tendência de imputar essa fórmula para o Brasil.

\section{Considerações Finais}

Os organismos internacionais, com destaque para o Banco Mundial e para a Organização de Cooperação para o Desenvolvimento Econômico, vêm 'traçando' a missão, os objetivos e o modus operandi das instituições de ensino superior. As diretrizes emanadas, em geral, recebem o aval dos governos, havendo, na maioria dos casos, um processo de mediação que procura conformar as orientações dos organismos às demandas do país e à oposição que se apresenta por meio de movimentos organizados como, por exemplo, os Sindicatos dos Docentes e dos Técnicos, os Diretórios e Centros Acadêmicos e, por vezes, até as associações de reitores.

As mudanças que vêm ocorrendo nas instituições de ensino superior têm mudado suas finalidades, objetivos, missão, formas de gestão, de financiamento e avaliação. Há uma grande preocupação em aproximar as instituições brasileiras do modelo de internacionalização desenhado pelos organismos internacionais, cujos objetivos centrais podem levar a uma privatização do conhecimento, por meio da constituição de um saber que esteja voltado para a valorização do capital.

A internacionalização, as orientações dos organismos internacionais, o processo de mundialização do capital e a sociedade do conhecimento vêm desempenhando um papel importante na definição do modelo de ensino superior que deva ser adotado. É evidente que a universidade e as demais instituições de ensino superior devem olhar para o mundo, para as suas necessidades, não se alienando no tempo no qual estão inseridas. Mas o destaque que se prioriza é a importância do papel que esse nível de ensino deve ter para a construção social, implicando isso a igualdade, o processo democrático, os interesses da maioria da sociedade, que devem ser o objetivo maior do ensino, da pesquisa e da extensão, sobretudo, nos países em desenvolvimento.

12 Destaque-se, em relação a recursos oriundos do governo, os casos da França (85\%), Espanha (80\%), Portugal (70\%) e da Itália (65\%). 


\section{REFERÊNCIAS}

BANQUE MONDIALE. Mondialistion, développement et pauvreté. Bâtir une économie intégrée. BM: Editions Eska, 2002.

BANQUE MONDIALE. Construire les sociétés du savoir. Nouveaux défis pour l'enseignement supérieur, Quebec: Presse Universitaire Laval, 2003.

BANQUE MONDIALE. Le défi d'établir des universités de rang mondial, 2009. Disponível em: http://siteresources.worldbank.org/EDUCATION/Resources/278200-1099079877269/547664-1099079956815/547670-1237305262556/World-Class_Universities_French.pdf. Acesso em: 06 ago. 2018.

BERNHEIM, C, T.; CHAUI, M. de S. Desafios da universidade na sociedade do conhecimento: Cinco anos depois da conferência mundial sobre educação superior. Brasília: UNESCO, 2008.

BIANCHETTI, L.; SGUISSARDI, V. Da Universidade à Commoditycidade. Ou de como e Quando, se a Educação/Formação é Sacrificada no Altar do Mercado, o Futuro da Universidade se Situaria em Algum Lugar do Passado. Campinas: Mercado de Letras, 2017.

BRASIL. Decreto n. 9.235, de 15 de dezembro de 2017. Dispõe sobre o exercício das funções de regulação, supervisão e avaliação das instituições de educação superior e dos cursos superiores de graduação e de pós-graduação no sistema federal de ensino. Diário Oficial da União, Brasília, 15 dez. 2017. Disponível em: http://www.planalto. gov.br/ccivil_03/_Ato2015-2018/2017/Decreto/D9235.htm. Acesso em: 05 mar. 2018.

CHAUI, M. A universidade pública sob nova perspectiva. Revista Brasileira de Educação, n. 24, p. 5-15, 2003.

CHESNAIS, F. Mundialização do Capital. São Paulo: Editora Xamã, 1996.

DUARTE, N. Sociedade do Conhecimento ou Sociedade das Ilusões? Quatro ensaios crítico-dialéticos em filosofia da educação. Campinas: Autores Associados, 2008. Coleção Polêmicas do Nosso Tempo.

HARNECKER, M. La gauche à l'aube du XXIème siècle. Rendre possible l'impossible. Quebec: Michel Brulé (Editions), 2002.

MARI, C. L. "Sociedade do Conhecimento" e Educação Superior na década de 1990: O Banco Mundial e a produção do desejo irrealizável de Midas. 2006. 265 f. Tese (Doutorado em Educação) - Universidade Federal de Santa Catarina, Florianópolis, 2006.

MÉSZÁROS, I. Para Além do Capital. Rumo a uma teoria da transição. Tradução Paulo Cesar Castanheira e Sergio Lessa. São Paulo: Boitempo, 2002. 1102 p.

MINISTÉRIO DA EDUCAÇÃO - MEC. Instituto Nacional de Estudos e Pesquisas Educacionais Anísio Teixeira - INEP. Censo da Educação Superior 2016. Notas Estatísticas. Disponível em: http://download.inep.gov.br/educacao_superior/censo_superior/ 
documentos/2016/notas_sobre_o_censo_da_educacao_superior_2016.pdf. Acesso em: 02 jul. 2017.

NEVES, R. C. L. Governança para uma Universidade de Classe Mundial: desafios e perspectivas. 2016. 156 f. Dissertação (Mestrado Profissional em Administração-MPA) - Universidade Federal de Pernambuco, Recife, 2016.

OCDE. Quatre Scénarios sur l'Avenir de l'Enseignement Supérieur. 2006. Disponível em: http://www.oecd.org/fr/education/educeri/38073746.pdf. Acesso em: 02 out. 2018.

. L'Enseignement Supérieur au Service de la Société de la Connaissance. 2008. Disponível em: http://ifgu.auf.org/media/document/40345193.pdf. Acesso em: 07 mar. 2018.

. L'enseignement supérieur à l'horizon 2030: Mondialisation. Centre pour la recherche et l'innovation dans l'enseignement, Éditions OCDE, 2011.

OLIVEIRA, D. A. Nova Gestão Pública e Governos Democrático-Populares: Contradições entre a busca da eficiência e a ampliação do direito à educação. Educação $e$ Sociedade, Campinas, v. 36, n. 132, p. 625-646, jul./set. 2015

PAULA, M. F. C. USP e UFRJ. A influência das concepções alemã e francesa em suas fundações. Tempo Social, S. Paulo, v. 14, n. 2, p. 147-161, out. 2002.

SANTOS, A. V.; GUIMARÃES-IOSIF, R.; CHAVES, V. L. Corporações privadas na educação superior brasileira: Implicações das novas práticas organizacionais. Arquivos Analíticos de Politicas Educativas, v. 26, n. 136, p. 2-21, 2018.

SILVA JÚNIOR, J. R. The New Brazilian University. A busca por resultados comercializáveis: para quem? Bauru: Canal Editora, Projeto Editorial Práxis, 2017.

SLAUGHTER, S.; LESLIE, L. Academic capitalism: politics, policies, and the entrepreneurial university. Baltimore, Maryland: Johns Hopkins University Press, 1997.

SILVEIRA, Zuleide Simas da; BIANCHETTI, Lucídio. Universidade moderna: dos interesses do Estado-nação às conveniências do mercado. Revista Brasileira de Educação, Rio de Janeiro, v. 21, n. 64, p. 79-99, jan./mar. 2016.

THEIS, I. M. A Sociedade do conhecimento realmente existente na perspectiva do desenvolvimento desigual. URBE-Revista Brasileira de Gestão Urbana, Curitiba, v. 5, n. 1, p. 133-148, jan./jun. 2013.

THIENGO, L. C. Entrevista com Lara Carlette Thiengo, tese de doutorado "Universidades de Classe Mundial e o Consenso pela Excelência: Tendências Globais e Locais" (UFSC). Anped, Rio de Janeiro, 03 maio 2018. Disponível em: http://www.anped.org. $\mathrm{br} /$ news/entrevista-com-lara-carlette-thiengo-tese-de-doutorado-universidades-de-classe-mundial-e-o. Acesso em: 02 jun. 2018.

THIENGO, L. C.; BIANCHETTI, L.; MARI, C. L. Obsessão pela Excelência. Universidade de Classe Mundial no Brasil? Revista Internacional de Educação Superior, v. 4, 
n. 3, p. 716-745, set./dez. 2018.

UNIVERSIDADE DE SÃO PAULO -USP. Criando as bases para a USP do Futuro. Relatório Final. 2016. Disponível em: https://www.adusp.org.br/files/democracia\%20 na\%20usp/LAI/rel_fase1.pdf. Acesso em: 07 set. 2018.

Texto recebido em 12 de abril de 2019.

Texto aprovado em 30 de abril de 2019. 